\title{
Taller
}

\section{Herramientas para compartir información en Internet: Google Docs, Dropbox, Twitter y RSS}

\author{
J. Bravo Acuña \\ Pediatra. Miembro de EI GIPI. CS El Greco. Getafe, Madrid. España.
}

\section{INTRODUCCIÓN}

En este documento y en el taller, seminario o charla para el que lo estamos redactando, queremos dar a conocer algunas herramientas gratuitas, de fácil manejo y accesibles a través de Internet que nos permiten hacer más fácil la tarea de recibir y compartir la información. Pero queremos aclarar algo:

- Que sean gratuitas, es decir que no nos cuesten dinero, no quiere decir que no tengan un precio, porque todas ellas requieren un registro previo y la aceptación de las condiciones del servicio.

- De fácil manejo quiere decir que cualquiera que utilice un ordenador a diario, use el correo electrónico, navegue por Internet y maneje los programas más habituales para elaborar textos o presentaciones puede sacar partido a estas herramientas. Este texto y el taller están dirigidos a pediatras con ese perfil de usuario, no va dirigido a quienes tienen dificultades con la informática ni a los que ya usan estas aplicaciones.

- Que sean accesibles en Internet quiere decir que son aplicaciones que no requieren, salvo excepciones, instalación en nuestro ordenador, de modo que se puede acceder a ellas y utilizarlas desde cualquier ordenador o dispositivo móvil que disponga de conexión a Internet.
La idea es que aquellos que estén interesados puedan conocer estas herramientas y sus posibilidades, para que puedan decidir si les pueden ser útiles. Esperamos que sea así.

\section{母}

\section{RECIBIR INFORMACIÓN: LOS RSS}

RSS en Wikipedia: http://es.wikipedia.org/wiki/ RSS; RSS in plain English (YouTube): www.youtube. com/watch?v=DQ_UL-5rYXO

\section{¿Qué son?}

Podemos explicarlo de una forma simple si decimos que son archivos que contienen información de las novedades que se publican en las páginas web, blogs, canales de video o cualquier otro recurso que podamos encontrar en Internet. Generalmente, esas novedades aparecen en orden inverso a la fecha de publicación, de modo que siempre tendremos lo más reciente a la vista. En la Wikipedia podemos encontrar una explicación de lo que son los RSS, cuyas siglas corresponden a really simple syndication, que viene a querer decir, en traducción libre, algo así como "compartir la información es fácil". En un vídeo disponible en YouTube lo explican de una manera práctica y sencilla. 


\section{¿Para qué sirven?}

Su interés reside precisamente en su contenido, ya que hemos dicho que contenían las novedades de las páginas web, lo que permite que con solo acceder al archivo RSS de una página sepamos qué hay de nuevo en ella sin tener que recorrerla de cabo a rabo. Es cierto que algunas páginas pueden tener una sección de novedades que podría cumplir esa función, pero los RSS permiten, además, que, si nos interesa recibir la información, podamos suscribirnos al mismo, de modo que cada vez que se produzca una novedad en la web y se publique en el RSS, la recibamos sin demora. Para poder suscribirnos y recibir los RSS necesitaremos una aplicación que nos lo permita. Se trata de los agregadores o lectores de RSS. De entre los más conocidos y usados actualmente destacamos: Google Reader, iGoogle y Netvibes.

\section{Google \\ GOOGLE READER}

Google: www.google.es/; Google Reader: www. google.es/reader

Es un producto de la factoría Google y para disponer de él no necesitamos más que una cuenta de Google que requiere registro. Es una aplicación gratuita, disponible on-line desde cualquier ordenador o dispositivo móvil conectado a Internet, sin necesidad de instalar nada, que nos permite suscribirnos a los RSS que queramos, de modo que podamos recibir y organizar, de una manera sencilla, la información.

\section{$i$ Google}

\section{IGOOGLE}

iGoogle: www.google.es/ig

También de la misma factoría, o sea, una aplicación on-line gratuita, que requiere registro o, lo que es lo mismo, una cuenta en Google. Tampoco necesita ninguna instalación. Pretende ser nuestra pantalla de inicio, porque permite que personalicemos la pantalla de búsqueda de Google con aqueIlo que nos resulte útil, entre otras cosas, con los RSS que nos interesen. La información aparece como ventanas con titulares y podemos agruparla en pestañas. Una de sus características interesantes es la posibilidad de enviar alguna de nuestras pestañas a otros usuarios para que, si lo desean, la incorporen a su propia aplicación.

En el momento en el que estamos escribiendo esto, iGoogle está inmerso en un proceso de renovación, que esperemos sea para bien.

\section{+ netvibes}

\section{NETVIBES}

Netvibes: www.netvibes.com; El gipi-RSS: www. netvibes.com/elgipi; Asociación Española de Pediatría (AEP): www.netvibes.com/aepediatria; Asociación Española de Vacunología (AEV): www.net vibes.com/aev

Es otra aplicación gratuita, que requiere registro. Similar a iGoogle, que también permite compartir las pestañas, pero con una característica que lo hace diferente y es que nos ofrece la posibilidad de crear un perfil público, al que puede acceder cualquiera sin necesidad de registro, con lo que podemos publicar nuestra página web con la información de los RSS de las webs que hayamos seleccionado. Interesante, ¿no?

Así hemos creado la página El gipi-RSS con información de interés pediátrico, la de la AEP, en la que agrupamos toda la información de las diferentes páginas web de la AEP y de sus diferentes RSS, su página de Facebook y sus cuentas de Twitter, o la de la AEV. 


\section{Dropbox}

\section{COMPARTIR INFORMACIÓN: DROPBOX}

Dropbox: www.dropbox.com; Dropbox: presentación: http://slidesha.re/w9dgne

\section{¿Qué es?}

De manera simple podríamos decir que se trata de un disco duro virtual, ya que permite disponer de un espacio de 2,5 Gigabytes en Internet en el que poder almacenar los archivos o carpetas que queramos, con lo que disponemos de una copia de seguridad de nuestros archivos que estarán accesibles a través de cualquier ordenador o dispositivo conectado a Internet. Es, como hemos comentado, gratuita, disponible en español y, aunque requiere registro, solo solicita una dirección de correo válida.

\section{¿Para qué sirve?}

Entre otras utilidades, nos puede servir de copia de seguridad, de almacén compartido y de plataforma para publicar archivos o crear una galería de imágenes en Internet.

Copia de seguridad: para sacar el máximo partido a la aplicación es aconsejable instalar el programa en uno o varios ordenadores, y así disponer de los mismos archivos en ese o esos ordenadores y en el almacén de Internet. Para subir los archivos al almacén virtual, solo tenemos que guardarlos en la carpeta correspondiente de nuestro ordenador y, si estamos conectados a Internet, se actualizará en el almacén y en cada ordenador o dispositivo móvil en el que tengamos instalado el programa.

Almacén compartido: porque aparte de esa función de almacenaje, también permite compartir archivos y carpetas con otros usuarios de Dropbox, de modo que podemos tener un almacén compartido, muy útil, por ejemplo, para evitar enviar los archivos por correo.

Publicación de archivos o de una galería de imágenes en Internet: por si fuera poco, por defecto, en el espacio del almacén y de nuestro ordenador, disponemos de dos carpetas: Public y Photos, que permiten crear enlaces públicos a archivos (Public) o carpetas de imágenes (Photos) de modo que es como si publicáramos en Internet, ya que podrá acceder cualquiera que disponga del enlace, sin necesidad de tener una cuenta de Dropbox.

Si queremos disponer de más espacio podemos hacerlo pagando una cantidad mensual, aunque es posible llegar a triplicar el espacio gratuito si se lo recomendamos a nuestros amigos o conocidos y estos crean una cuenta en Dropbox e instalan el programa en algún ordenador, porque tanto a cada uno de ellos, como a nosotros, nos regalarán 250 MB más de espacio.

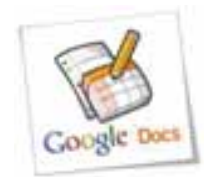

\section{COMPARTIR INFORMACIÓN Y TRABAJAR EN EOUIPO: GOOGLE DOCS}

GoogleDocs: https://docs.google.com/

\section{¿Qué es?}

Otra herramienta de la que podemos disfrutar con solo tener una cuenta de Google. Aunque puede considerarse un disco duro virtual y utilizarse como almacén de archivos, ya que ofrece hasta 1 Gigabyte de espacio, su principal utilidad es la de ser una suite ofimática de uso on-line, que nos permite, sin necesidad de instalar ningún programa y desde cualquier ordenador conectado a Internet, crear y editar documentos de texto, presentaciones, archivos de Excel, formularios, tablas o dibujos, y, si es necesario, descargarlos a nuestro ordenador en diferentes formatos.

\section{¿Para qué sirve?}

A diferencia de Dropbox, que es un estupendo sistema de almacenaje, Google Docs ofrece muchas posibilidades para el trabajo en equipo ya que se comparten archivos o carpetas (colecciones), pero 
además se pueden editar de manera simultánea o secuencial (síncrona o asíncrona), según nos parezca, de modo que muchas personas pueden intervenir en la elaboración de un documento, presentación u otro tipo de archivo.

Los permisos de acceso que podemos conceder a los documentos de Google Docs pueden variar desde acceso limitado a nosotros mismos, permitir el acceso a algunas personas para que puedan ver pero no editar, permitir la edición e, incluso, hacerlos públicos en Internet a través de un enlace.

Esta versatilidad es la que hace de Google Docs una de las herramientas más útiles para el trabajo en equipo.

Queremos destacar un tipo de documentos, los formularios, porque permiten crear de manera sencilla documentos para la recogida de datos o la realización de encuestas, que se pueden publicar en Internet o incrustar en páginas web. Además, la aplicación se encarga de que las respuestas que se vayan produciendo al formulario vayan rellenando, de manera automática, los campos de la tabla correspondiente, $y$, por si fuera poco, nos ofrece estadísticas básicas con los resultados.

Todo un mundo de posibilidades.

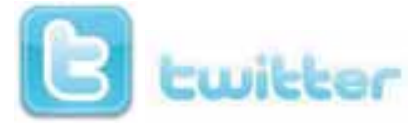

\section{RECIBIR Y COMPARTIR INFORMACIÓN: TWITTER}

Twitter: http://twitter.com; Twittersfera Sanitaria: http://wikisanidad.wikispaces.com/Twittersfera +Sanitaria

\section{¿Qué es?}

Una aplicación web gratuita, aunque requiere registro, que permite a sus usuarios escribir y publicar pequeños textos (de hasta 140 caracteres) que pueden ser leídos por cualquiera que acceda a la página. Algo así como un blog en pequeño. Mu- chos mensajes consisten en un texto y algún enlace, pero pueden incluir imágenes.

Cada cuenta de Twitter tiene un nombre de usuario que comienza con un símbolo de @, por ejemplo@aepap.

Además, permite recibir los mensajes de otras personas a las que hayamos decidido seguir.

\section{¿Para qué sirve?}

Para recibir la información que publiquen aquellas personas o cuentas de Twitter a las que sigamos y compartir la información que hayamos decidido publicar con las personas que nos sigan.

\section{¿Cómo funciona?}

Es más difícil explicarlo que comenzar a usarlo [-]. Tras un registro sencillo podemos crear una cuenta que puede ser privada o pública. Nuestra recomendación es que sea pública, pero podemos elegir. Si la cuenta es pública, cualquier mensaje que publiquemos podrá ser visto por todo aquel que visite la dirección http://twitter. com/nombredeusuario, mientras que nosotros, con solo visitar la página http://twitter.com y utilizar la aplicación con nuestro nombre de usuario y contraseña, podremos leer los mensajes de aquellas cuentas que sigamos. Si queremos compartir algún mensaje que recibamos con nuestros seguidores podemos reenviarlo o hacer un retweet (RT) con o sin un comentario añadido, aunque también podemos contestar algún mensaje de manera pública.

La aplicación también permite enviar mensajes directos (privados) a cualquiera de nuestros seguidores.

Para organizar la información que recibimos podemos ordenar las cuentas que seguimos en listas.

Son muchas las cuentas de Twitter que pueden interesar a los pediatras que se inician en esta aplicación. Algunas de ellas están incluidas en el directorio de la Twittersfera Sanitaria, un buen lugar para conocer usuarios interesantes.

Los múltiples usos que se le pueden dar a Twitter, junto con las numerosas aplicaciones que, basadas 
en esta aplicación, le añaden valor y utilidades hacen que un texto como este se quede corto para explicar los entresijos de la aplicación.

\section{REFLEXIÓN FINAL}

Si con este breve texto y con el taller correspondiente conseguimos que los pediatras que aún no lo han hecho se interesen por estas herramientas que les permitan recibir y compartir información de forma sencilla y práctica habremos conseguido nuestro objetivo.

\section{CONFLICTO DE INTERESES}

Los autores declaran no presentar conflictos de intereses en relación con la preparación y publicación de este artículo.

\section{ABREVIATURAS}

AEP: Asociación Española de Pediatría • AEV: Asociación Española de Vacunología • RSS: really simple syndication.

Nota: los nombres y logos citados aquí a título informativo son marcas registradas con los derechos reservados por y para sus propietarios en los términos que determina la normativa legal aplicable. 